\title{
Paediatric chronic recurrent multifocal osteomyelitis
}

\author{
Davy R Wong, ${ }^{1}$ Geoffrey R Wong, ${ }^{2}$ Bishoy Moussa, ${ }^{3}$ Megan T Ang ${ }^{4}$
}

${ }^{1}$ School of Medicine, University of Notre Dame Australia, Sydney, New South Wales, Australia

${ }^{2}$ Royal Melbourne Hospital, Melbourne, Victoria, Australia ${ }^{3}$ Department of Anaesthesia, Royal Children's Hospital Melbourne, Melbourne, Victoria, Australia

${ }^{4}$ Department of Radiology, Alfred Health, Melbourne, Victoria, Australia

\section{Correspondence to} Dr Geoffrey R Wong, geoffrey.wong@adelaide.edu. $\mathrm{au}$

Accepted 29 January 2017

\section{DESCRIPTION}

A previously healthy girl aged 15 years presented with a 3-month history of low back pain, lethargy, morning stiffness and nocturnal back discomfort. She had no significant history of weight loss, infective symptoms or neurological symptoms, including bladder or bowel incontinence. There was no recent travel history.

Examination revealed normal temperature and mild focal tenderness over the midline lumbar spine, with normal range of motion. There was isolated weakness in left hip flexion, and no other neurological findings. Blood tests showed a normal white cell count $\left(6.6 \times 10^{9} / \mathrm{L}\right)$, elevated erythrocyte sedimentation rate $(38 \mathrm{~mm} /$ hour $)$ and slightly elevated $\mathrm{C}$ reactive protein $(11 \mathrm{mg} / \mathrm{L}$, normal $<10 \mathrm{mg} /$ L). X-rays were unremarkable. A limited CT of L3 showed diffuse sclerosis of its spinous process with areas of lytic destruction and mild effacement of the paravertebral fat pads (figure 1). Serial blood cultures were negative for microorganisms. Subsequent empirical antibiotics with intravenous flucloxacillin were initiated for presumed infective osteomyelitis.
Further assessment with MRI lumbar spine showed an abnormality at the L3 level, with expansion of the L3 lamina and spinous process, and an area of low T1 signal with corresponding high T2 signal within (figure 2). There was enhancement of this area postcontrast imaging, and adjacent paraspinal oedema without features of malignancy. Whole-body bone scan demonstrated focal abnormal uptake in the L3 spinous process, left sacral ala, left ilium and right proximal tibia (figure 3). Given the multifocality of the metabolically active bone lesions, combined with the relatively benign history and normal biochemistry, the diagnosis of chronic recurrent multifocal osteomyelitis (CRMO) was made. Antibiotics were ceased after 3 days and the patient underwent treatment with non-steroidal anti-inflammatory drugs (NSAIDs), followed by a tapering regimen of prednisolone $10 \mathrm{mg}$ and physical therapy. At 6 months follow-up, she experienced a significant reduction in symptoms and improved quality of life.

CRMO is a rare auto-inflammatory disorder which typically affects children (median age
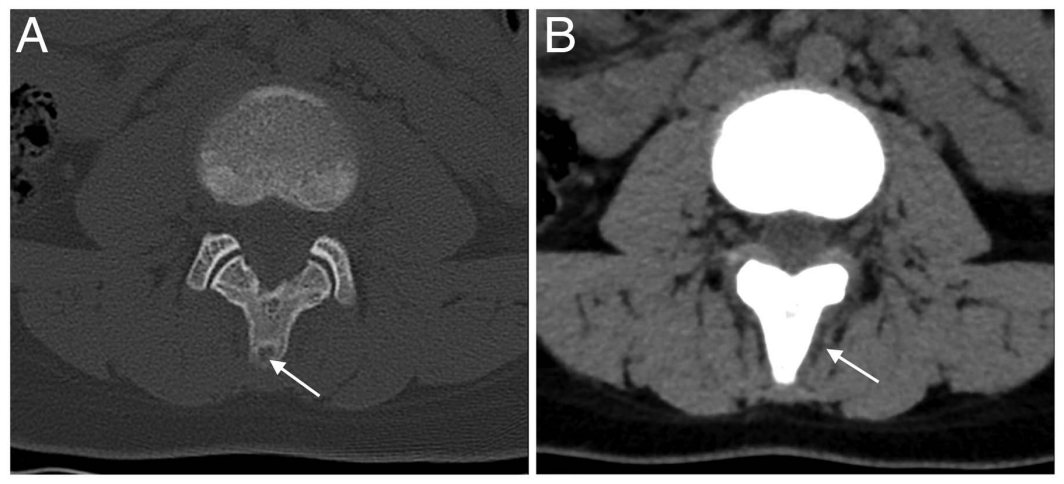

Figure 1 CT lumbar spine. Axial view. Bone window demonstrating diffuse sclerosis of the L3 spinous process with areas of lytic destruction ( $A$-white arrow). (B) Soft tissue window showing mild effacement of the paravertebral fat pads adjacent to the spinous process (B-white arrow).
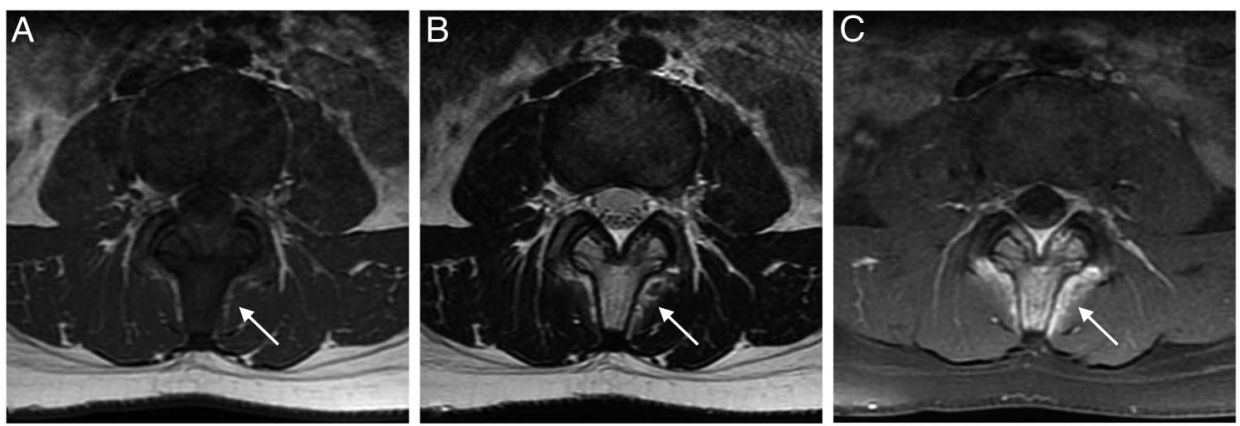
Wong GR, Moussa B, et al.
BMJ Case Rep Published online: [please include Day Month Year] doi:10.1136/ bcr-2016-218957

Figure 2 MRI lumbar spine. Axial view T1 (A) and T2 (B) weighted sequences demonstrating expansion and diffuse oedema in the $L 3$ spinous process, with enhancement postcontrast (C). This was associated with adjacent soft tissue swelling and oedema (white arrows). 


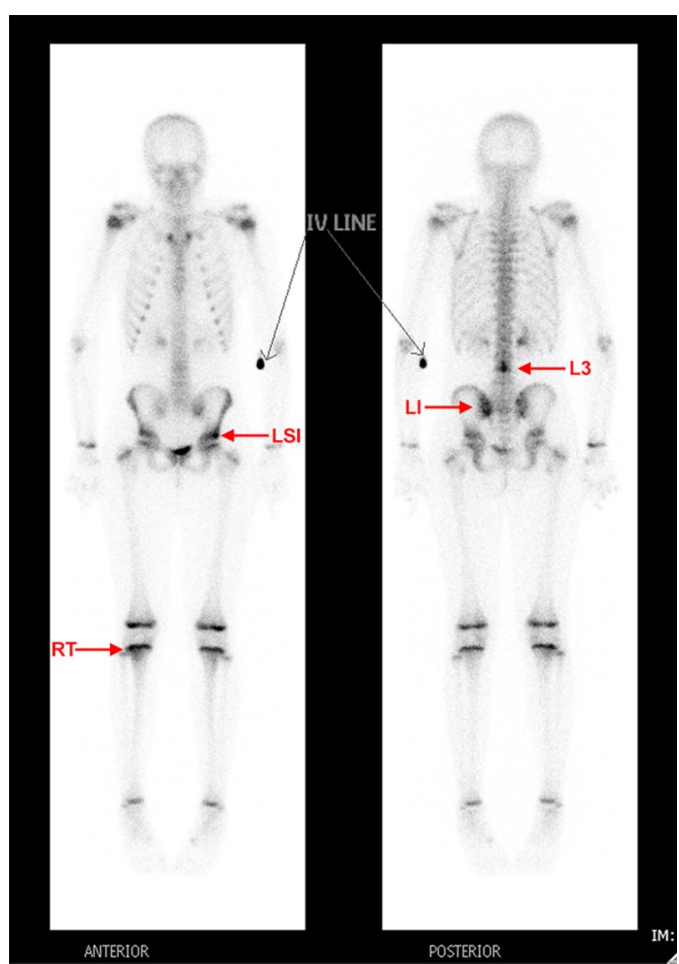

Figure 3 Whole-body bone scan. Anterior and posterior view. Bone scintigraphy showing focal abnormal radiopharmaceutical uptake (red arrows) in the L3 spinous process (L3), left sacroiliac joint (LSI), left ilium (LI) and right proximal tibia (RT).

10 years old). CRMO is characterised by non-bacterial multifocal osseous lesions which may mimic chronic osteomyelitis. It is often seen in the metaphysis of long bones, clavicles, vertebral bodies and pelvis. ${ }^{1}$ There may be an association with several autoimmune diseases such as psoarisis, inflammatory bowel disease and granulomatosis.

A combination of imaging techniques such as plain radiographs, MRI and bone scintigraphy are useful in the diagnosis of CRMO. As CRMO is a diagnosis of exclusion, it may be difficult to exclude diagnoses such as infective osteomyelitis and neoplasms on imaging alone, and biopsies can be considered for confirmation. MRI is useful in CRMO monitoring highlighting the extent of disease as it is highly sensitive and specific for inflammatory abnormalities. Other advantages include no ionising radiation and better characterisation of bone marrow lesions. ${ }^{2}$
NSAIDs are considered the most suitable treatment of CRMO, and in $80 \%$ of patients have been shown to relieve symptoms. ${ }^{3}$ In cases of relapse and recurrent symptoms in patients with NSAID treatment, other pharmaceutical interventions such as bisphosphonates, corticosteroids, methotrexate, interferon and TNF- $\alpha$ inhibitors have shown some efficacy. ${ }^{1}$

\section{Learning points}

- Chronic back pain in children should be investigated promptly and include a careful and thorough clinical assessment for paediatric red flags.

- Initial imaging with an X-ray should be performed. MRI and bone scintigraphy are useful adjuncts to aid in the early diagnosis of chronic recurrent multifocal osteomyelitis (CRMO) to avoid unnecessary invasive diagnostic tests or aggressive therapy.

- CRMO is a rare non-bacterial disease with multifocal lesions. It is identified in long tubular bones, clavicle and pelvis and most commonly in long bone metaphyseal lesions. Importantly, infection and malignancy should be excluded.

- Combination treatment may be required in treating CMRO. First-line therapy with non-steroidal anti-inflammatory drugs should be considered, and if relapse occurs, disease-modifying agents such as methotrexate, bisphosphonates and corticosteroids may be used.

Contributors MTA and GRW were responsible for study concept and design. All the authors were responsible for analysis and interpretation of the data. DRW, GRW and BM contributed to drafting of the manuscript. MTA, DRW and GRW contributed to critical revision.

Competing interests None declared.

Patient consent Obtained.

Provenance and peer review Not commissioned; externally peer reviewed.

\section{REFERENCES}

1 Hofmann SR, Schnabel A, Rösen-Wolff A, et al. Chronic non-bacterial osteomyelitis: pathophysiological concepts and current treatment strategies. J Rheumatol 2016:43:1956-64.

2 Jurik AG. Chronic recurrent multifocal osteomyelitis. Semin Musculoskelet Radiol 2004;8:243-53.

3 Girschick HJ, Raab P, Surbaum S, et al. Chronic nonbacterial osteomyelitis in children. Ann Rheum Dis 2005;64:279-85.

Copyright 2017 BMJ Publishing Group. All rights reserved. For permission to reuse any of this content visit http://group.bmj.com/group/rights-licensing/permissions.

BMJ Case Report Fellows may re-use this article for personal use and teaching without any further permission.

Become a Fellow of BMJ Case Reports today and you can:

- Submit as many cases as you like

- Enjoy fast sympathetic peer review and rapid publication of accepted articles

- Access all the published articles

- Re-use any of the published material for personal use and teaching without further permission

For information on Institutional Fellowships contact consortiasales@bmjgroup.com

Visit casereports.bmj.com for more articles like this and to become a Fellow 